\title{
ALTERAÇÃO AMBIENTAL E CRESCIMENTO DE Araucaria angustifolia (Bertol.) Kuntze NA REGIÃO CENTRO-SUL DO PARANÁ, BRASIL
}

\author{
Amanda Köche Marcon ${ }^{1}$, Franklin Galvão ${ }^{2}$, Paulo Cesar Botosso ${ }^{3}$, Christopher \\ Thomas Blum², Milena Kozlowski ${ }^{4}$ \\ ${ }^{1}$ Doutoranda do Programa de Pós-graduação em Engenharia Florestal, Universidade \\ Federal do Paraná, Curitiba - PR, Brasil (amandakoche@gmail.com) \\ ${ }^{2}$ Professor Doutor do Programa de Pós-graduação em Engenharia Florestal, Universidade \\ Federal do Paraná, Curitiba - PR, Brasil \\ ${ }^{3}$ Pesquisador Doutor na Empresa Brasileira de Pesquisa Agropecuária (Embrapa Florestas), \\ Colombo - PR, Brasil \\ ${ }^{4}$ Graduanda em Engenharia Florestal, Universidade Federal do Paraná, Curitiba - PR, Brasil
}

Recebido em: 22/09/2018 - Aprovado em: 23/11/2018 - Publicado em: 03/12/2018 DOI: 10.18677/EnciBio 2018B4

\section{RESUMO}

Alterações ambientais podem implicar mudanças nas características de um ecossistema e alterar a vegetação local, sobretudo o crescimento das espécies. Este estudo objetivou avaliar o crescimento de Araucaria angustifolia em relação a uma alteração ambiental, ocorrida com a implantação de lagoas artificiais nas proximidades dos indivíduos, nos anos de 1974 e 1976. Foram coletadas duas amostras radiais diametralmente opostas do lenho de nove indivíduos adultos de $A$. angustifolia, com o uso de um trado de incremento. As amostras foram processadas seguindo a metodologia clássica de dendrocronologia. Para avaliar as mudanças no crescimento de cada indivíduo foram calculados os incrementos em área basal. As relações entre o crescimento radial e o clima, para os períodos anterior e posterior à alteração ambiental, foram analisadas a partir de testes de correlação entre a cronologia e os dados históricos mensais de precipitação pluviométrica e temperatura média, utilizando o coeficiente de Pearson. O incremento em área basal individual indicou um aumento no crescimento em período próximo à alteração ambiental para algumas das árvores. A correlação entre os índices dos anéis de crescimento e os dados meteorológicos históricos indica uma resposta distinta entre os períodos anterior e posterior à implantação das lagoas. Pode-se inferir que a alteração ambiental, associada a outros fatores, como a temperatura no verão e a precipitação no verão e no inverno, modificou alguns padrões de resposta no seu crescimento.

PALAVRAS-CHAVE: Anéis de Crescimento, Dendrocronologia, Incremento em Área Basal.

\section{RESPONSES TO ENVIRONMENTAL CHANGE IN Araucaria angustifolia (Bertol.) Kuntze GROWTH IN THE SOUTH OF PARANÁ, BRAZIL}

\begin{abstract}
Environmental changes may imply some transformations in the characteristics of an ecosystem, especially in the plant species growth. This study aimed to evaluate Araucaria angustifolia growth in response to environmental change, which occurred with the implantation of artificial lakes, in the years 1974 and 1976. Two diametrically
\end{abstract}


opposed radial wood samples of nine adult individuals of Araucaria angustifolia were collected, using an increment borer. Wood samples were processed following the classical dendrochronology methodology. Basal area increment was calculated to evaluate changes in individual growth. Relationships between radial growth and climate, for the periods before and after the environmental change, were analyzed from correlation tests between chronology and monthly historical data of rainfall and average temperature, using the Pearson coefficient. Basal area increment showed a growth increase in the environmental change period for some trees. The correlation between tree ring growth and historical meteorological data indicates a distinct response between the periods before and after the artificial lakes. The results allow to infer that the environmental change, associated with other factors such as summer temperature and summer and winter precipitation, modified some patterns of response in its growth.

KEYWORDS: Dendrochronology, Basal Area Increment, Tree Rings.

\section{INTRODUÇÃO}

A espécie Araucaria angustifolia (Bertol.) Kuntze (Araucariaceae) surgiu há milhões de anos e passou por grandes mudanças climáticas até os tempos atuais (ZANETTE et al., 2017). O aumento da temperatura e da umidade, há cerca de 6.000 a 4.000 anos, favoreceu a expansão da espécie, contudo a ocupação dos campos nos planaltos do Sul do Brasil tem apenas 1.500 anos (ZANETTE et al., 2017). A. angustifolia é uma espécie arbórea de grande porte, nativa do Brasil, e seu habitat natural consiste em locais de clima frio com ocorrência de geadas, altitudes elevadas e precipitação bem distribuída ao longo do ano (MACHADO et al., 2015; FRITZSONS et al., 2018).

As características do ambiente podem interferir nos crescimentos primário e secundário das espécies arbóreas. As maiores taxas de crescimento para $A$. angustifolia são encontradas em solos com boas condições de aeração e drenagem - mas com água disponível - disponibilidade de nutrientes e profundidade para desenvolvimento de suas raízes (ABRÃO et al., 2017). Além disso, a espécie se desenvolve melhor em ambiente com maior luminosidade, sendo sua regeneração mais expressiva em clareiras ou outros ambientes abertos (ZANETTE et al., 2017).

Alterações ambientais causadas por ação humana podem implicar supressão ou inserção de novos elementos no ambiente, modificando processos naturais ou sociais (SÁNCHEZ, 2013). Nesse contexto, a inserção de lagoas artificiais pode causar alterações no clima local, no solo, na estrutura da vegetação, entre outros (ESTEVES, 2011; SIMÕES et al., 2015; CRUZ et al., 2016). Ainda existem lacunas no conhecimento no que diz respeito aos efeitos destes impactos ambientais nos ecossistemas como, por exemplo, a respeito dos impactos da mudança no nível da água, nos nutrientes, na temperatura e quais os bens e serviços podem ser modificados (JEPPESEN et al., 2015).

Tendo em vista a enorme importância econômica, ambiental e cultural de $A$. angustifolia e a necessidade de abordagens que avaliem as alterações ambientais com o uso de séries temporais existentes (JEPPESEN et al., 2015; SANQUETTA et al., 2016), com este estudo buscou-se avaliar o crescimento de algumas árvores da espécie em relação à alteração ambiental ocorrida no local, com a implantação de lagoas artificiais. Nesse contexto, procurou-se responder as questões: i) A dendrocronologia pode ser uma ferramenta para detectar alterações ambientais? e ii) A implantação de lagoas artificiais interfere no crescimento de $A$. angustifolia? 


\section{MATERIAL E MÉTODOS}

O estudo foi realizado na localidade de Faxinal do Céu, no município de Pinhão, estado do Paraná, em área de propriedade da Companhia Paranaense de Energia (COPEL). A área de estudo está localizada entre as coordenadas 25 54' $58^{\prime \prime}$ e $25^{\circ} 55^{\prime} 06^{\prime \prime} \mathrm{S}$ e $51^{\circ} 36^{\prime} 00^{\prime \prime}$ e $51^{\circ} 35^{\prime} 44^{\prime \prime} \mathrm{O}$, com altitude média de $1.150 \mathrm{~m}$ s.n.m.

O clima da região está inserido na unidade climática $C f b$, de acordo com a classificação de Köppen (ALVARES et al., 2013). Essa unidade caracteriza-se por apresentar verões brandos e invernos intensos, com frequente ocorrência de geadas e sem estação seca definida, sendo classificado como subtropical úmido.

A vegetação predominante é classificada como Floresta Ombrófila Mista Montana, formação florestal dominada por gêneros como Araucaria, Drymis e Podocarpus (IBGE, 2012). No Sul do Brasil, a formação ocorre atualmente em mosaicos entremeados por áreas de campos, naturais ou antrópicos (DALLABRIDA et al., 2017).

No ano de 2016 foram coletadas duas amostras radiais de lenho diametralmente opostas de nove indivíduos de $A$. angustifolia, com o uso de um trado de Pressler (5 mm de diâmetro), à altura do DAP (diâmetro a altura do peito $1,30 \mathrm{~m}$ do solo). As árvores amostradas encontravam-se isoladas ou em pequenos agrupamentos, próximas a três reservatórios d'água artificiais, decorrentes de barramento ou represamento de cursos d'água naturais (definição conforme a Lei № 12.651/2012), tratados neste estudo como lagoas artificiais. As lagoas artificiais têm tamanho aproximado de $16.600,1.400$ e $930 \mathrm{~m}^{2}$, e, de acordo com relatos dos habitantes locais, foram construídas em 1974 e 1976.

As amostras foram submetidas à secagem em temperatura ambiente e fixadas sobre suportes de madeira, visando o polimento superficial da seção transversal, com uso de lixas de diferentes granulometrias (80 a $1.000 \mathrm{grãos} / \mathrm{cm}^{2}$ ). Os anéis de crescimento foram delimitados com auxílio de uma lupa estereomicroscópica e, posteriormente, as amostras foram digitalizadas (resolução de 1.200 dpi) com uso de um scanner HP Scanjet G4050. As larguras dos anéis de crescimento foram mensuradas em milímetros, utilizando um programa de processamento de imagens.

Procedeu-se com a datação cruzada visual dos anéis de crescimento entre raios de uma mesma árvore, analisando-se graficamente os dados de incremento anual no programa Microsoft Office Excel. Posteriormente, a qualidade da datação dos anéis foi verificada através do programa COFECHA® (HOLMES, 1983), que permite identificar anéis faltantes, anéis falsos e erros na datação. Esse controle foi realizado entre raios de uma mesma árvore e entre os indivíduos, adotando-se um segmento de análise (janela) de 20 anos com sobreposição de 10 anos. As cronologias de anéis de crescimento são construídas a partir da remoção das tendências biológicas de crescimento, realizada por uma padronização e transformação das larguras dos anéis de crescimento em índice (FRITTS, 1976). Neste estudo, a padronização foi realizada utilizando uma função spline dependente da idade (age dependent spline), no programa RCSigFree (COOK et al., 2018). Para avaliar a qualidade da cronologia foram gerados: o índice Sinal Expresso da População (EPS) e o coeficiente de correlação Rbar. O EPS demonstra o sinal comum em uma cronologia em comparação com uma cronologia infinitamente replicada e o Rbar é o coeficiente de correlação médio entre cada série e a cronologia (WIGLEY et al., 1984; BRIFFA, 1995). 
Para avaliar as mudanças individuais no crescimento foram calculados os incrementos em área basal (IAB) (BIONDI; QEADAN, 2008), conforme equação (1).

$$
l A B_{t}=\pi R_{t}^{2}-\pi R_{t-1}^{2}
$$
anterior.

Onde $R_{t}$ é o tamanho do raio no ano $t$ e $R_{t-1}$ é o tamanho do raio no ano

As relações entre o crescimento radial e o clima, para os períodos anterior e posterior à alteração ambiental, foram analisadas a partir de testes de correlação entre a cronologia construída e os dados históricos mensais de precipitação pluviométrica e temperatura média, utilizando o coeficiente de Pearson. A precipitação pluviométrica foi obtida da estação meteorológica Jangada do Sul (COPEL), compreendendo o período de 1945 a 2014. Os dados históricos de temperatura são provenientes do banco de dados do National Oceanic \& Atmospheric Administration Earth System Research Laboratory - NOAA/ESRL (KALNAY, 1996), para o período de 1956 a 2014.

\section{RESULTADOS E DISCUSSÃO}

As árvores estudadas possuem idades entre 39 e 59 anos (Tabela 1). Dos nove indivíduos inicialmente amostrados, foi possível sincronizar e utilizar seis nestas análises. Problemas como dificuldades na secagem da amostra em função de grã irregular e/ou baixa sincronia entre árvores em função da presença de anéis falsos, ausentes ou anéis em cunha impossibilitaram a utilização de três árvores neste estudo. Alguns trabalhos (OLIVEIRA et al., 2017; HAINES et al., 2018), também evidenciaram alguma dificuldade em realizar a sincronização dos anéis de crescimento entre árvores do gênero Araucaria por essas mesmas razões.

TABELA 1. Estatística descritiva da cronologia dos anéis de crescimento de Araucaria angustifolia na região centro-sul do Paraná, Brasil.

\begin{tabular}{lc}
\hline Descrição & Cronologia \\
\hline Série master & $1956-2014$ \\
Número de séries datadas & $12(16)^{*}$ \\
Número de indivíduos & $6(9)^{\star}$ \\
Comprimento das series (anos) & $39-59$ \\
Total de anéis & 462 \\
Total de anéis datados & 462 \\
Intercorrelação das séries & 0,327 \\
Correlação crítica (p<0,01) & 0,515 \\
Sensibilidade média & 0,331 \\
\hline
\end{tabular}

*número inicial de séries datadas e indivíduos amostrados, entre parênteses.

Fonte: Os Autores, 2018.

Como as amostras foram coletadas em abril de 2016, o último anel com crescimento completo datado corresponde ao ano de 2014. Isso ocorre no hemisfério Sul, pois, como o período quente inicia em agosto/setembro, a estação de crescimento, ou período vegetativo, inicia em um ano e termina no ano seguinte (KANIESKI et al., 2017).

A cronologia de A. angustifolia compreendeu o período de 1956 a 2014, possibilitando avaliar as respostas no crescimento em relação à alteração ambiental, que teve início no ano de 1974 (Figura 1C). 


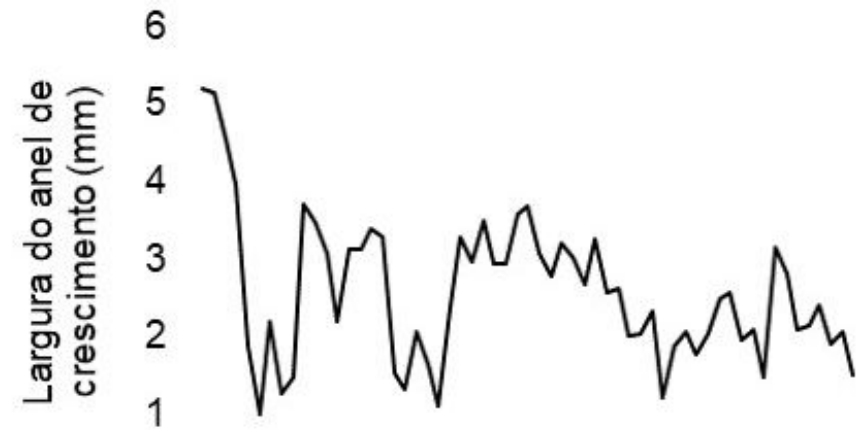

A

0

B
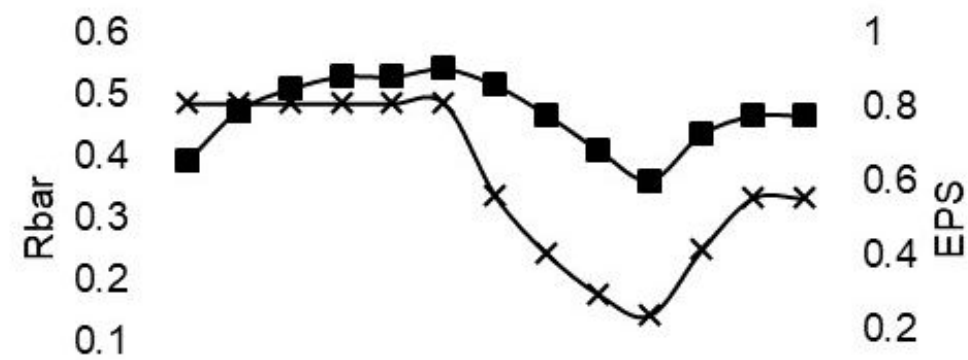

0

0

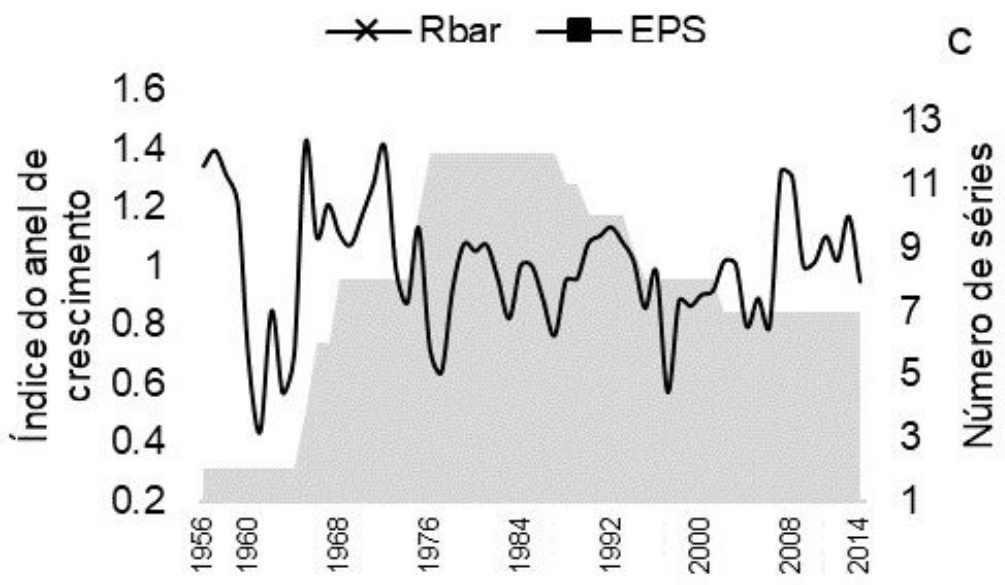

FIGURA 1. (A) Largura dos anéis de crescimento ( $\mathrm{mm})$; (B) EPS e Rbar e (C) cronologia e número de séries por período (área em cinza) para Araucaria angustifolia na região centro-sul do Paraná, Brasil.

(Fonte: Os Autores, 2018)

Os valores de EPS obtidos indicam que a cronologia representa satisfatoriamente o sinal da população (Figura 1B). O valor médio de EPS para a cronologia foi de 0,77 . Wigley et al. (1984) sugerem que o EPS é adequado quando superior a 0,85. Entretanto, segundo Piraino et al. (2015), esse critério pode ser ajustado dependendo das características ecológicas das espécies analisadas, especialmente em regiões tropicais. Outro parâmetro de avaliação da cronologia, a sensibilidade média (Tabela 1), que indica a capacidade da população em registrar alterações ambientais, é considerada alta ( $>0,3$ de acordo com Grissino-Mayer, 2001). Embora a intercorrelação das séries temporais não tenha atingido a correlação crítica, estes resultados indicam que a cronologia possui qualidade satisfatória e pode ser utilizada para avaliar as relações com o ambiente. 
O incremento em área basal individual, obtido após a datação e sincronização dos anéis de crescimento, indica mudanças no padrão de crescimento no período correspondente à alteração ambiental para as árvores 1, 2, 3 e 5 (Figura 2). 0 incremento em área basal é adequado para avaliar mudanças individuais, pois representa o crescimento da árvore como um todo. Por essa razão é melhor do que uma representação linear, como o incremento em diâmetro ou a largura do anel de crescimento (BIONDI; QEADAN, 2008).

Observa-se um aumento do incremento em área basal, que pode estar relacionado às mudanças ocorridas no ambiente onde as árvores se encontram. Esse comportamento também é observado na largura média dos anéis de crescimento (Figura 1A), onde um expressivo aumento na largura dos anéis ocorre a partir do ano de 1979.

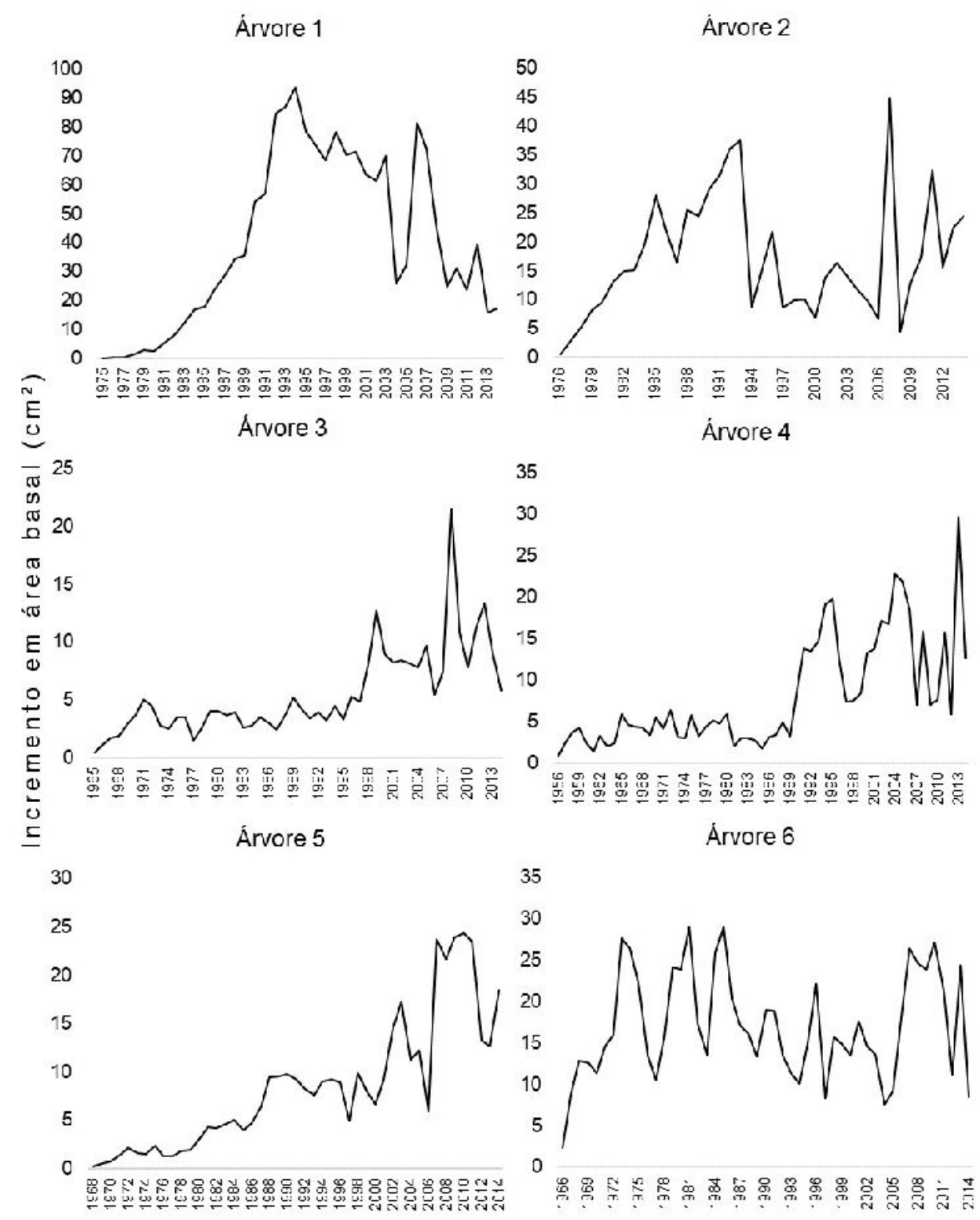

FIGURA 2. Séries temporais de incremento em área basal de árvores de Araucaria angustifolia na região centro-sul do Paraná, Brasil.

(Fonte: Os Autores, 2018) 
Pode-se inferir que o aumento no incremento em área basal, observado na maioria dos indivíduos avaliados, nas proximidades dos anos 1974-1976 está relacionado às alterações ambientais ocorridas no local.

A espécie $A$. angustifolia é exigente em termos de condições edáficas, sendo mais comumente encontrada em solos profundos, bem drenados e férteis (MARCON et al., 2014; OLIVEIRA et al., 2016). Uma hipótese para a ocorrência dessa liberação de crescimento pode estar relacionada com a retirada do restante da vegetação do entorno desses indivíduos. De acordo com o mapa elaborado a partir de levantamento aerofotogramétrico da região, realizado entre 1971-1974 pelo Instituto Brasileiro de Desenvolvimento Florestal, no local onde foi realizada a coleta das amostras havia uma Floresta Ombrófila Mista secundária de baixa densidade (IBDF, 1974). Considerando o melhor desenvolvimento da espécie $A$. angustifolia em solos férteis, a retirada da vegetação ao redor dessas árvores pode ter reduzido a competição por nutrientes e facilitado o crescimento desses indivíduos. É importante ressaltar que o quanto uma árvore cresce em diâmetro em determinado período está diretamente ligado ao espaço de crescimento de que a árvore dispõe (CURTO et al., 2017). Quanto menor o espaço disponível, maior a competição, já que a competição é um processo ecológico dependente da densidade (GUREVITCH et al., 2009).

As alterações ocasionadas por lagos artificiais vêm sendo abordadas em pesquisas recentes, principalmente relacionando quais variáveis ambientais seriam afetadas (CRUZ et al., 2016; HOPPE; WOLMANN, 2018). Além da redução na competição entre árvores, pode-se inferir que a implantação das lagoas favoreceu 0 crescimento das árvores em função do aumento na umidade do solo. Como as árvores amostradas encontram-se bastante próximas das lagoas, pode ter ocorrido uma maior disponibilidade hídrica, que aliada à redução na competição teria favorecido o crescimento das árvores. Embora a amplitude das alterações no regime hidrológico em função de reservatórios artificiais dependa do tamanho da obra, da área de inundação e da espessura da lâmina d'água, um dos efeitos notórios é o maior volume de água, em solos que anteriormente possuíam menores teores de umidade (ALBUQUERQUE FILHO; LEITE, 2002). Quando o lençol freático atinge cota máxima no ambiente, as raízes das plantas do entorno ficam mais próximas da água, situação favorecida se a declividade do terreno for pequena (CURCIO et al., 2007).

Durante o período de crescimento, fatores como: disponibilidade hídrica, temperatura e luminosidade favorável elevam as taxas fotossintéticas (BACHTOLD; MELO-JUNIOR, 2015; CASTRO et al., 2017). Essa maior síntese de compostos orgânicos promovem uma maior taxa de divisão das células do meristema cambial, resultando em maior crescimento diamétrico (CASTRO et al., 2017).

Campelo et al. (2015) avaliaram as trocas gasosas e a taxa fotossintética em indivíduos arbóreos adultos de espécies florestais em função do suprimento de água no solo. Os autores verificaram que há redução nas taxas fotossintéticas causadas pelo fechamento estomático provocado pelo estresse hídrico, porém essa resposta pode variar em função da sensibilidade da espécie em situação de déficit de água.

A correlação entre os índices dos anéis de crescimento e os dados históricos de precipitação e temperatura indica uma resposta distinta entre os períodos anterior e posterior à implantação das lagoas (Figura 3). 


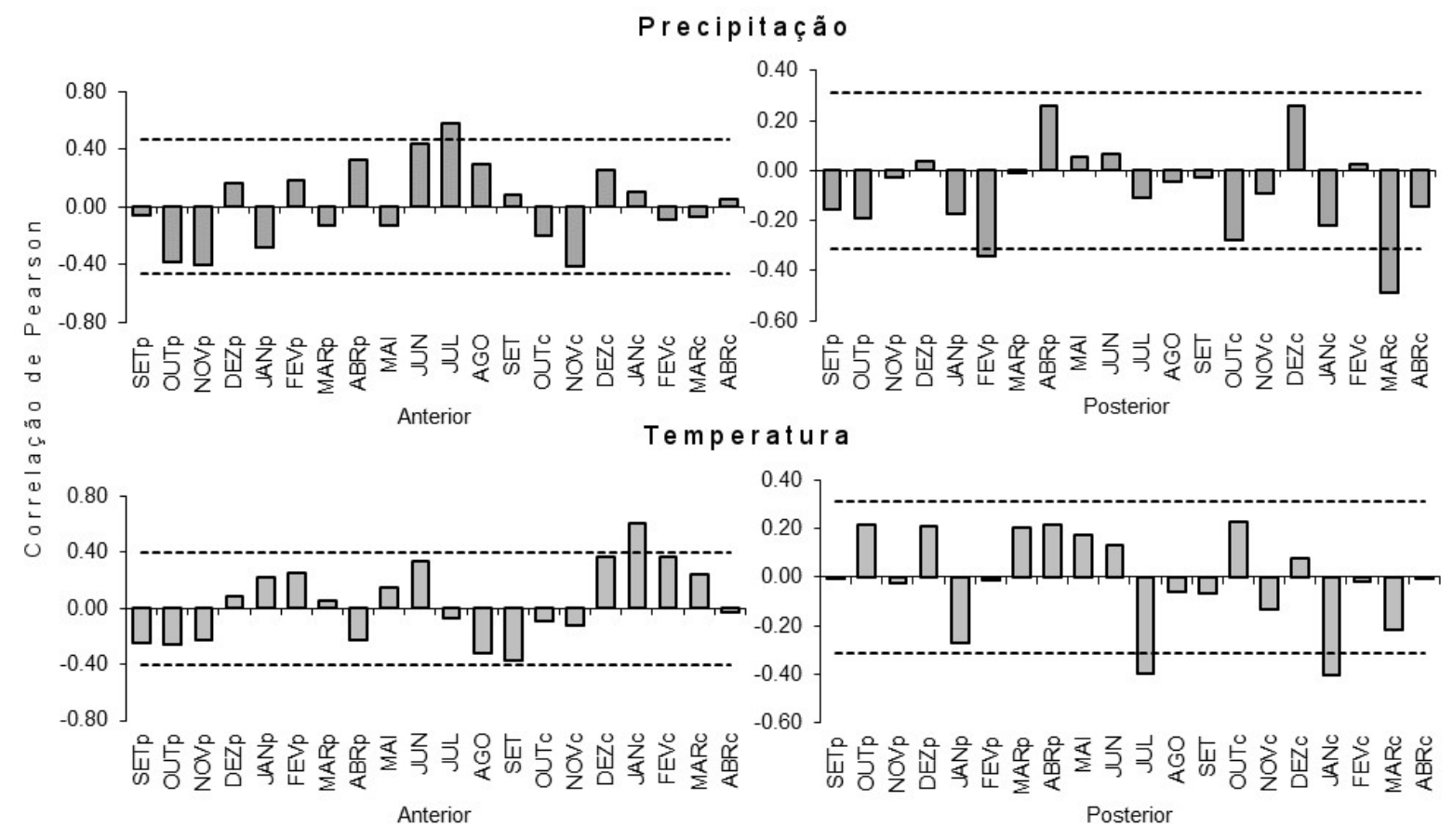

FIGURA 3. Correlação entre precipitação e temperatura e a cronologia de anéis de crescimento de $A$. angustifolia para os períodos anterior e posterior à implantação das lagoas artificiais. As linhas em pontilhado representam o limite de significância $(p<0,05)$. A letra $p$ junto ao mês indica ano prévio e a letra c indica ano corrente.

(Fonte: Os Autores, 2018)

O padrão geral para precipitação manteve-se nos períodos anterior e posterior, porém observa-se uma mudança nos meses onde as correlações foram significativas. No período anterior tem-se uma correlação significativa positiva $(p<0,05)$ da precipitação com o crescimento no mês de julho do ano corrente, que não ocorre no período posterior. Esse resultado pode estar relacionado com a umidade no solo no período mais seco do ano na região, o inverno. No período anterior, é possível que a umidade do solo fosse menor e as chuvas ocasionavam um aumento no crescimento. No período posterior esse efeito não é observado, podendo estar associado a maior umidade no solo em função das lagoas próximas às árvores. Para Esteves (2011), um dos efeitos da implantação de lagos artificiais é a elevação do lençol freático e o consequente aumento da umidade do solo.

A precipitação nos meses de fevereiro prévio e março apresentaram correlações significativas negativas $(p<0,05)$ com 0 crescimento no período posterior. Esse resultado pode indicar que o excesso de chuvas nesses meses reduziu as taxas de crescimento após a implantação das lagoas. O acúmulo de água pode ter efeitos negativos para plantas não adaptadas, principalmente durante a brotação e estação de crescimento (HERTER et al., 2014), em função do déficit de oxigênio (BONFIM-SILVA et al., 2015).

Lorensi e Prestes (2018), avaliando o crescimento de A. angustifolia em Santa Catarina, encontraram uma relação negativa entre a precipitação e o crescimento, em uma situação de grande volume de precipitação no inverno. Entretanto, os autores encontraram correlações positivas com a precipitação no verão, indicando 
que outros fatores ambientais locais podem influenciar as respostas das plantas à variação climática.

Os resultados dos testes de correlação do crescimento com as temperaturas indicam uma inversão no padrão de resposta no verão do ano corrente. Enquanto no período anterior à implantação das lagoas tem-se uma relação significativa positiva com a temperatura de janeiro, no período posterior a relação se inverte. As árvores estarem dentro da floresta no período anterior, sofrendo menos com elevadas temperaturas, e isoladas ou em pequenos grupos no período posterior - mais susceptíveis a altas intensidades de insolação e altas temperaturas - é uma hipótese para explicar esse comportamento. Segundo Townsend et al. (2006), intensidades elevadas de radiação podem causar fotoinibição e superaquecimento, prejudicando o crescimento.

Martinkoski et al. (2015), em revisão bibliográfica sobre o crescimento de $A$. angustifolia, concluíram que, de forma geral, quanto maiores os volumes de precipitação e maior a temperatura média durante a estação de crescimento, maiores os incrementos em diâmetro. Contudo, os autores reforçam que essas relações parecem estar bastante atreladas as condições de sítio, corroborando com o observado neste estudo, onde mudanças nas condições ambientais locais podem ter alterado as respostas climáticas no crescimento.

\section{CONCLUSÃO}

Observou-se um aumento do incremento em área basal nas proximidades dos anos 1974-1976, que pode estar relacionado às mudanças ocorridas no ambiente.

A correlação entre os índices dos anéis de crescimento e os dados meteorológicos históricos indica uma resposta distinta entre os períodos anterior e posterior à implantação das lagoas.

Pode-se inferir que a alteração ambiental decorrente da formação dos reservatórios (lagoas), associada a outros fatores, modificou alguns padrões de resposta no crescimento.

\section{AGRADECIMENTOS}

Os autores gostariam de agradecer a Companhia Paranaense de Energia (COPEL) pela autorização para realização deste estudo e pelo apoio logístico fornecido durante as coletas de dados e ao Conselho Nacional de Desenvolvimento Científico e Tecnológico pela concessão de bolsa de estudos à primeira autora e bolsa de produtividade em pesquisa ao segundo autor.

\section{REFERÊNCIAS}

ABRÃO, S. F.; RIZZI, N. E.; PELISSARI, A. L.; MACHADO, S. A. Influência das condições ambientais no crescimento de dois grupos arbóreos em Floresta com Araucária. BIOFIX Scientific Journal, v. 2, n. 2, p. 10-15, 2017. Disponível em: $<$ https://revistas.ufpr.br/biofix/article/view/53634>. dx.doi.org/10.5380/biofix.v2i2.53634

doi:

ALBUQUERQUE FILHO, J. L.; LEITE, C. B. B. Elevações induzidas no lençol freático devido a formação de reservatórios e o significado das modificações resultantes. Geociências, v. VII, n. 6, p. 69-74, 2002. Disponível em: <http://revistas.ung.br/index.php/geociencias/article/view/1442>. 
ALVARES, C. A.; STAPE, J. L.; SENTELHAS, P. C.; GONÇALVES, J. L. M.; SPAROVEK, G. Köppen's climate classification map for Brazil. Meteorologische Zeitschrift, v. 22, n. 6, p. 711-728, 2013. Disponível em: $<$ https://www.schweizerbart.de/papers/metz/detail/22/82078/Koppen_s_climate_clas sification_map_for_Brazil>.

BACHTOLD, B. A.; MELO-JUNIOR, J. C. F. Plasticidade morfológica de Calophyllum brasiliense Camb. (Calophyllaceae) em duas formações de restinga no sul do Brasil. Acta Biológica Catarinense, v. 2, n. 2, p. 21-32, 2015. Disponível em: <http://periodicos.univille.br/index.php/ABC/article/view/21-32>.

BIONDI, F.; QEADAN, F. A Theory-Driven Approach to Tree-Ring Standardization: Defining the Biological Trend from Expected Basal Area Increment. Tree-Ring Research, v. 64, n. 2, p. 81-96, 2008. Disponível em: <http://www.bioone.org/doi/abs/10.3959/2008-6.1>.

BONFIM-SILVA, E. M.; KROTH, B. E.; SILVA, T. J. A.; KOETZ, M. Desenvolvimento inicial de pinhão-manso sob disponibilidades hídricas do solo. Irriga, Botucatu, $v$. 20, n. $1, \quad$ p. 73-81, 2015. Disponível em: <https://doi.org/10.15809/irriga.2015v20n1p73>. doi: 10.15809/irriga.2015v20n1p73

BRIFFA, K. R. Interpreting high-resolution proxy climate data: the example of dendroclimatology. In: H. von Storch; A. Navarra (Eds.); Analysis of climate variability, applications of statistical techniques. p.77-94, 1995. New York: Springer Berlin Heidelberg.

CAMPELO, D. H.; LACERDA, C. F.; SOUSA, J. A.; CORREIA, D.; ESMERALDO, A. $M$. et al. Trocas gasosas e eficiência do fotossistema II em plantas adultas de seis espécies florestais em função do suprimento de água no solo. Revista Árvore, v. 39, n. 5, p. 973-983, 2015. Disponível em: <http://dx.doi.org/10.1590/010067622015000500020>. doi: 10.1590/0100-67622015000500020

CASTRO, V. R.; SURDI, P. G.; TOMAZELLO FILHO, M.; CHAIX, G.; LACLAU, J. P. Efeito da disponibilidade hídrica e da aplicação de potássio e sódio no crescimento em diâmetro do tronco de árvores de Eucalyptus grandis. Scientia Forestalis, v. 45, n. 113, p. 89-99, 2017. Disponível em: <http://dx.doi.org/10.18671/scifor.v45n113.08>. doi: 10.18671/scifor.v45n113.08

COOK, E. R.; KRUSIC, P. J.; MELVIN, T. Program RCSigFree. Disponível em: $<$ http://www.ldeo.columbia.edu/tree-ring-laboratory/resources/\%0Asoftware $>$. Acesso em: 14/08/2018.

CRUZ, A. R.; TEIXEIRA, C. S.; PEREIRA, J. A.; AMORIM, R.; PINHEIRO, J. R. Impacto causado pela implantação de Usina Hidrelétricas e PCH'S na Amazônia Meridional. Revista Eletrônica Geoaraguaia, v. 6, n. 1, p. 19-29, 2016. Disponível em: <http://periodicoscientificos.ufmt.br/ojs/index.php/geo/article/view/4934>.

CURCIO, G. R.; SOUSA, L. P.; BONNET, A.; BARDDAL, M. L. Recomendação de espécies arbóreas nativas, por tipo de solo, para recuperação ambiental das 
margens da represa do rio Iraí, Pinhais, PR. Floresta, v. 37, n. 1, p. 113-122, 2007. Disponível em: <http://revistas.ufpr.br/floresta/article/view/7847>. doi: 10.5380/rf.v37i1.7847

CURTO, R. A.; BRAZ, E. M.; MATTOS, P. P.; NETTO, S. P. Critérios para o manejo de plantios de araucária para a produção madeireira. In: I. Wendling; F. Zanette (Eds.); Araucária: particularidades, propagação e manejo de plantios. p.145159, 2017. Brasília: EMBRAPA.

DALLABRIDA, J. P.; SILVA, A. C.; HIGUCHI, P.; SOUZA, K.; LOEBENS, R. et al. Elementos nucleadores da paisagem influenciam a dispersão zoocórica em áreas campestres alto-montanas. Rodriguésia, v. 68, n. 2, p. 325-335, 2017. Disponível em: $\quad<$ http://dx.doi.org/10.1590/2175-7860201768204>. doi: 10.1590/21757860201768204

ESTEVES, F. A. Fundamentos de Limnologia. 3rd ed. Rio de Janeiro: Editora Interciência, 2011. 826 p.

FRITTS, H. C. Tree Rings and Climate. San Diego: Academic Press, 1976. 567 p.

FRITZSONS, E.; MANTOVANI, L. E.; WREGE, M. S. Fatores climáticos limitantes da distribuição da Araucária no estado do Paraná e as implicações para sua restauração. Revista Ra'e Ga, v. 44, p. 258-271, 2018. Disponível em: $<$ https://dx.doi.org/10.5380/raega>. doi: 10.5380/raega

GRISSINO-MAYER, H. D. Evaluating Crossdating Accuracy: A Manual and Tutorial for the Computer Program COFECHA. Tree-Ring Research, v. 57, n. 2, 2001. TreeRing Society. Disponível em: <http://hdl.handle.net/10150/251654>.

GUREVITCH, J.; SCHEINER, S. M.; FOX, G. A. Ecologia Vegetal. 2nd ed. Porto Alegre: Artmed, 2009. 592 p.

HERTER, F. G.; WREGE, M. S.; TONIETTO, J.; FLORES, C. A. Adaptação Edafoclimática. In: M. C. B. Raseira; J. F. M. Pereira; F. L. C. Carvalho (Eds.); Pessegueiro. p.45-56, 2014. Brasília: EMBRAPA.

HOLMES, R. Computer-assisted quality control in tree-ring dating and measurement. Tree-ring bulletin, v. 43, p. 69-78, 1983. Disponível em: <http://arizona.openrepository.com/arizona/bitstream/10150/261223/1/trb-43-069078.pdf>. Acesso em: 26/06/2017.

HOPPE, I. L.; WOLMANN, C. A. Análise da precipitação pluviométrica e a presença de nevoeiros no entorno próximo do reservatório da Usina Hidrelétrica de Dona Francisca em Agudo/RS. Revista Brasileira de Climatologia, v. 22, p. 133-148, 2018. Disponível em: <https://revistas.ufpr.br/revistaabclima/article/view/55425/34853>.

IBDF - Instituto Brasileiro de Desenvolvimento Florestal. Levantamento aerofotogramétrico da região da "Araucaria angustifolia". Brasília, 1974. 
IBGE - Instituto Brasileiro de Geografia e Estatística. Manual Técnico da Vegetação Brasileira. $2^{\mathrm{a}}$ edição ed. Rio de Janeiro, 2012.

JEPPESEN, E.; BRUCET, S.; NASELLI-FLORES, L.; PAPASTERGIADOU, ; E.; STEFANIDIS, K. et al. Ecological impacts of global warming and water abstraction on lakes and reservoirs due to changes in water level and related changes in salinity. Hydrobiologia, v. 750, n. 1, p. 201-227, 2015. Disponível em: <http://link.springer.com/10.1007/s10750-014-2169-x>. doi: 10.1007/s10750-0142169-x

KALNAY, E. . C. The NCEP/NCAR Reanalysis 40-year Project. Bulletin of the American Meteorological Society, v. 77, p. 437-471, 1996.

KANIESKI, M. R.; GALVÃO, F.; ROIG, F. A.; BOTOSSO, P. C. Dendroecologia de Sebastiania commersoniana (Baill.) L.B.Sm. \& Downs E Hovenia dulcis Thunb. em uma área degradada na Floresta Ombrófila Mista Aluvial, Sul do Brasil. Ciência Florestal, v. 27, n. 4, p. 1201-1215, 2017. Disponível em: $<$ http://www.scielo.br/scielo.php?script=sci_arttext\&pid=S1980-

50982017000401201>.

LORENSI, C.; PRESTES, A. Dendroclimatologia com amostras de Araucaria angustifolia coletadas em Santa Catarina. Revista Univap, v. 24, n. 44, p. 1-12, 2018. Disponível em: <http://dx.doi.org/10.18066/revistaunivap.v24i44.424>. doi: 10.18066/revistaunivap.v24i44.424

MACHADO, S. D. A.; ACCIOLY, Y.; NASCIMENTO, R. G. M.; SILVA, L. C. R. DA; CARDOZO, C. C. Influência do comprimento de copa na relação hipsométrica de Araucaria angustifolia. Pesquisa Florestal Brasileira, v. 35, n. 83, p. 343, 2015. Disponível em: <http://pfb.cnpf.embrapa.br/pfb/index.php/pfb/article/view/493>. doi: 10.4336/2015.pfb.35.83.493

MARCON, A. K.; SILVA, A. C.; HIGUCHI, P.; FERREIRA, T. S.; MISSIO, F. F. et al. Variação florístico-estrutural em resposta à heterogeneidade ambiental em uma floresta nebular em Ububici, Planalto Catarinense. Scientia Forestalis, v. 42, n. 103, p. 439-450, 2014. Disponível em: <http://www.ipef.br/publicacoes/scientia/nr103/cap14.pdf>.

MARTINKOSKI, L.; VOGEL, G. F.; JADOSKI, S. O. Influência do clima no crescimento diamétrico de Araucária angustifolia: revisão bibliográfica. Revista Brasileira de Tecnologia Aplicada nas Ciências Agrárias, v. 8, n. 2, p. 104-111, 2015. Disponível em: <http://www.gnresearch.org/doi/10.5935/PAeT.V8.N2.12>. doi: 10.5935/PAeT.V8.N2.12

OLIVEIRA, J. C.; BAUM, C. A.; BECEGATO, V. A.; NETO, S. L. R.; LAVNITCKI, L. Uso de ferramentas SIG para análise de agrupamento florestal de Araucaria angustifolia em um fragmento de Floresta Ombrófila Mista no Parque Nacional de São Joaquim-SC. Revista Geográfica Acadêmica, v. 10, n. 2, p. 93-104, 2016. Disponível em: <http://dx.doi.org/10.18227/1678-7226rga.v10i2.3859>. doi: 
10.18227/1678-7226rga.v10i2.3859

PIRAINO, S.; ABRAHAM, E. M.; DIBLASI, A.; ROIG JUÑENT, F. A. Geomorphological-related heterogeneity as reflected in tree growth and its relationships with climate of Monte Desert Prosopis flexuosa DC woodlands. Trees, v. 29, n. 3, p. 903-916, 2015. Disponível em: <http://link.springer.com/10.1007/s00468-015-1173-8>. doi: 10.1007/s00468-0151173-8

SÁNCHEZ, L. E. Avaliação de Impactos Ambientais: conceitos e métodos. 2nd ed. São Paulo: Oficina de Textos, 2013. 584 p.

SANQUETTA, C. R.; DOLCI, M.; CORTE, A. P. D.; SANQUETTA, M. N. I.; PELISSARI, A. L. Estimação de volumes de Araucaria angustifolia (Bertol.) O. Kuntze por fatores de forma em classes diamétricas e modelos de regressão. Enciclopédia Biosfera, Centro Científico Conhecer, v. 13, n. 23, p. 588-597, 2016. Disponível em: <http://www.conhecer.org.br/enciclop/2016a/agrarias/estimacao.pdf>. doi: $10.18677 /$ Enciclopedia

SIMÕES, N. R.; NUNES, A. H.; DIAS, J. D.; et al. Impact of reservoirs on zooplankton diversity and implications for the conservation of natural aquatic environments. Hydrobiologia, v. 758 , n. 1, p. 3-17, 2015. Disponível em: $<$ https://dx.doi.org/10.1007/s10750-015-2260-y>. doi: 10.1007/s10750-015-2260-y

TOWNSEND, C. R.; BEGON, M.; HARPER, J. L. Fundamentos em Ecologia. Porto Alegre: Artmed Editora, 2006. 592 p.

WIGLEY, T. M. L.; BRIFFA, K. R.; JONES, P. D. On the Average Value of Correlated Time Series, with Applications in Dendroclimatology and Hydrometeorology. Journal of Climate and Applied Meteorology, v. 23, n. 2, p. 201-213, 1984. Disponível em: $<$ http://journals.ametsoc.org/doi/abs/10.1175/1520-

0450\%281984\%29023\%3C0201\%3AOTAVOC\%3E2.0.CO\%3B2>. doi: 10.1175/1520-0450(1984)023<0201:OTAVOC>2.0.CO;2

ZANETTE, F.; DANNER, M. A.; CONSTANTINO, V.; WENDLING, I. Particularidades e biologia reprodutiva de Araucaria angustifolia. In: I. Wendling; F. Zanette (Eds.); Araucária: particularidades, propagação e manejo de plantios. p.13-40, 2017. Brasília: EMBRAPA. 